\title{
Cancer Patients Interest in Participating in Cancer Rehabilitation
}

Emma Ohlsson-Nevo ${ }^{1,2,3}$, Ingrid Alkebro', Johan Ahlgren ${ }^{1,2,4}$

\author{
1Örebro University Hospital, Örebro, Sweden, ${ }^{2} \mathrm{HM}$, \\ ${ }^{2}$ Faculty of Medicin and Health, Örebro University, Sweden, \\ ${ }^{3}$ Centre for Health Care Sciences, Örebro County Council, Sweden
}

\section{Conclusions}

Psychoeducational support groups, lectures and mental support, were the most wanted rehabilitational activities for cancer patients.

Cancer rehabilitation are most important for women, younger patients, university educated and one year after diagnosis. Cancer rehabilitation did not attract mandatory educated and patients older than 70 years of age.

\section{Introduction}

Rehabilitation for cancer patients aims at prevent and reduce the physical, mental, social and existential consequences of a cancer disease and its treatment. Cancer rehabilitation efforts should give the patient support according to their individual needs to with the purpose to live as good life as possible.

The aim of this study is to describe rehabilitations needs, among cancer patients.

\section{Material and Methods}

A total of 1179 cancer patients diagnosed with 28 different cancer diagnoses between 150801-160701, were identified for a postal survey with the purpose to investigate their rehabilitation needs.

The response rate was $60 \%$ as 728 participated.

There were 15 rehabilitation activities listed; 4 physical, 6 mental and 5 social to choose from.

The 10 most wanted activities are presented.

\section{Results}

More than $25 \%$ of the women wanted to attend 10 activities. Men were interested in participation in 3 activities.

Patients younger than 50 years of age were most interested in cancer rehabilitation as half the group wanted to attend 7 activities.

The patients with only mandatory education had a small interest in rehabilitation. No activity attracted more than $23 \%$. Among the university educated $27-47 \%$ wanted to attend 10 of the activities

There was a larger interest in cancer rehabilitation one year after the diagnosis than earlier in the cancer trajectory.

Patients with breast and gynecologic diagnoses were interested in most activities. More than $25 \%$ wanted 10 activities. More than $25 \%$ of the patients with blood cancer wanted 7 rehabilitational activities, skin 6, gastro 6, prostate 4, colorectal 3, lung 3, head and neck 2. Among the urologic diagnoses, no activity attracted $25 \%$ of the patients.

\begin{tabular}{|c|c|c|c|c|c|c|c|c|c|c|c|}
\hline & & \multicolumn{2}{|c|}{ Sex } & \multicolumn{3}{|c|}{ Age } & \multicolumn{3}{|c|}{ Education } & \multicolumn{2}{|c|}{ Time from diagnosis } \\
\hline & $\begin{array}{l}\text { Total } \\
\text { n (\%) }\end{array}$ & $\begin{array}{l}\mathrm{F} \\
\%\end{array}$ & $\begin{array}{l}M \\
\%\end{array}$ & $\begin{array}{c}20-49 \\
\%\end{array}$ & $\begin{array}{c}50-69 \\
\%\end{array}$ & $\begin{array}{c}70-80+ \\
\%\end{array}$ & $\begin{array}{c}\text { Mandatory } \\
\%\end{array}$ & $\begin{array}{c}\text { Highschool } \\
\%\end{array}$ & $\begin{array}{c}\text { University } \\
\%\end{array}$ & $\begin{array}{c}6-12 \\
\%\end{array}$ & $\begin{array}{c}13-18 \\
\%\end{array}$ \\
\hline No & 728 & 316 & 412 & 64 & 299 & 365 & 227 & 215 & 187 & 408 & 315 \\
\hline Lectures about cancer & $222(30)$ & 33 & 30 & 50 & 36 & 22 & 23 & 34 & 40 & 27 & 35 \\
\hline Social worker & $212(29)$ & 36 & 25 & 66 & 36 & 20 & 19 & 38 & 34 & 27 & 33 \\
\hline Webb info/same & $198(27)$ & 32 & 25 & 56 & 36 & 19 & 19 & 38 & 34 & 27 & 35 \\
\hline Med yoga & $164(22)$ & 39 & 11 & 56 & 31 & 9 & 10 & 26 & 36 & 21 & 22 \\
\hline Psychologist & $155(21)$ & 30 & 16 & 58 & 27 & 17 & 11 & 26 & 33 & 20 & 24 \\
\hline Stress reducing/individual & $142(19)$ & 30 & 13 & 61 & 26 & 9 & 8 & 16 & 29 & 21 & 18 \\
\hline Cardio/group & $134(18)$ & 26 & 14 & 30 & 27 & 13 & 12 & 19 & 27 & 21 & 24 \\
\hline
\end{tabular}

